\title{
Spatial distribution pattern and sequential sampling plans for Bactrocera oleae (Gmelin) (Dip: Tephritidae) in olive orchards
}

\author{
A. Arbab, ${ }^{1}$ F. Mirphakhar ${ }^{2}$ \\ ${ }^{1}$ Department of Agricultural Entomology, Islamic Azad University, Takestan Branch, Takestan; \\ ${ }^{2}$ Department of Agricultural Entomology, Shahid Bahonar University, Kerman, Iran
}

\begin{abstract}
The distribution of adult and larvae Bactrocera oleae (Diptera: Tephritidae), a key pest of olive, was studied in olive orchards. The first objective was to analyze the dispersion of this insect on olive and the second was to develop sampling plans based on fixed levels of precision for estimating $B$. oleae populations. The Taylor's power law and Iwao's patchiness regression models were used to analyze the data. Our results document that Iwao's patchiness provided a better description between variance and mean density. Taylor's $b$ and Iwao's $\beta$ were both significantly more than 1 , indicating that adults and larvae had aggregated spatial distribution. This result was further supported by the calculated common $k$ of 2.17 and 4.76 for adult and larvae, respectively. Iwao's $\alpha$ for larvae was significantly less than 0 , indicating that the basic distribution component of $B$. oleae is the individual insect. Optimal sample sizes for fixed precision levels of 0.10 and 0.25 were estimated with Iwao's patchiness coefficients. The optimum sample size for adult and larvae fluctuated throughout the seasons and depended upon the fly density and desired level of precision. For adult, this generally ranged from 2 to 11 and 7 to 15 traps to achieve precision levels of 0.25 and 0.10 , respectively. With respect to optimum sample size, the developed fixed-precision sequential sampling plans was suitable for estimating flies density at a precision level of $D=0.25$. Sampling plans, presented here, should be a tool for research on pest management decisions of $B$. oleae.
\end{abstract}

Correspondence: Abbas Arbab, Department of Agricultural Entomology, Islamic Azad University, Takestan Branch, Takestan, Iran.

E-mail: abbasarbab@hotmail.com

Key words: Bactrocera oleae; spatial distribution; sample size; sequential sampling.

Received for publication: 26 September 2015.

Revision received: 19 January 2016.

Accepted for publication: 22 January 2016.

(c) Copyright A. Arbab and F. Mirphakhar, 2016

Licensee PAGEPress, Italy

Journal of Entomological and Acarological Research 2016; $48: 5533$

doi:10.4081/jear.2016.5533

This article is distributed under the terms of the Creative Commons Attribution Noncommercial License (by-nc 4.0) which permits any noncommercial use, distribution, and reproduction in any medium, provided the original author(s) and source are credited.

\section{Introduction}

The olive fruit fly Bactrocera oleae (Gmelin) (Diptera: Tephritidae) is the most serious insect pest of olive fruits in the world. It is known primarily from the Mediterranean area of southern Europe, and is also found in North Africa, the Middle East, and along the east coast of Africa to South Africa. It is generally agreed among olive fly researchers that this insect can survive and develop in any area of the world where olive trees are grown (Economopoulos, 2002; Eliopoulos, 2008; Daane \& Johnson, 2010). This monophagous pest was first detected in 2004 in north of Iran, develops three generations per year with wide overlap in them (Jafari \& Rezaee, 2005). It is able to reduce crop yield in several ways. Adult females injure drupes through their oviposition on the ripening fruits. The newly hatched larva will grow as a fruit borer, excavating a tunnel in the mesocarp until pupation. Larval feeding on the mesocarp causes yield loss primarily by pulp consumption and inducing premature fruit dropping (Corrado et al., 2012). Additionally they are creating channels inside the fruit while feeding, they tunnel throughout the fruit, allowing entry of secondary infestation of bacteria and fungi that rot the fruit and decrease the oil quality and quantity, also greatly increase the free fatty acid level (acidity) of the oil olive (Pavlidi et al., 2013). It has been estimated that the average crop loss is in the range of $5-30 \%$ of the total olive production, even with intense chemical control measures (Corrado et al., 2012).

Effective and sustainable management of the olive fruit fly is a challenge. The most widespread management technique in Iran is the use of the hydrolyzed protein (\%3) mixed with 0.001 concentration of deltamethrin (2.5\%), an insecticidal bait that is acceptable for organic production (Noori, 2011). The bait application is recommended once a week to alternate rows of trees in the treated orchard. Sanitation (i.e., removing fruits after harvest) is an important cultural control for the olive fruit fly in olive orchards, but it is time consuming and expensive (Villamil et al., 2013). No effective natural enemies have been found to date in Iran. Experimental data have shown that spraying entomopathogenic nematodes such as Steinernema feltiae over fallen olives may prove to be a good control technique for larvae in the soil and inside fallen olives (Sirjani et al., 2009). Mating disruption, which involves the release of great quantities of sex pheromone to interfere with male's ability to find females in the field, is a potential approach for olive fruit fly management (Villamil et al., 2013). Yellow sticky tape plus pheromone is one of the common and effective methods for sampling and mass trapping of olive fruit fly (Montiel-Bueno, 1986; Caleca et al., 2006; Burrack et al., 2008). Studies on spatial patterns of Tephritidae are scarce and are mostly based on trap counts. Examples include spatial patterns of the Mediterranean fruit fly, Ceratitis capitata (Wiedemann) using large grid of traps with trimedlure (Israely et al., 2005), spatial distribution of adults of B. oleae (Gmelin) in olive orchards using food attractant-based traps (Dimou et al., 2003), spatial 
and temporal patterns of $B$. dorsalis (Hendel) adults captured in traps and described by indices of dispersion and regression models (Soemargono et al., 2011).

Information about changes in population density of $B$. oleae during the season, identification of factors influencing population fluctuations and determination of their impacts on productivity will be critical to assisting olive producers in management of this pest. The spatial distribution of populations is affected by the dispersal abilities of the species, interactions among individuals, or habitat selection (Vinatier et al., 2011). Knowledge of the spatial distribution of arthropods provides useful information not only for theoretical population biology but is also critical for field monitoring programs (Arbab, 2014; Arbab \& McNeill, 2014). No field sampling can be efficient without understanding the underlying spatial distribution (Taylor, 1984). Understanding the spatial distribution of insect pests also allows for the estimation of densities while minimizing data collection costs which in turn form the basis for making decision in pest management (Khaing et al., 2002; Fernandes et al., 2011). Methods that are commonly used to describe dispersion of insects and other arthropod populations have been summarized by Southwood (1995). Two regression models, Taylor and Iwao, depend on the relationship between the sample mean and the variance of insect numbers per sampling unit through time, and provide a stable relationship from one year to another based on only the observed sampling mean (Bisseleua et al., 2011).

In developing a suitable sampling program for research or pest management purposes, it is necessary to determine two characteristic features of any population, its density and its dispersion (Pedigo \& Buntin, 1994). In this regard, little is known about the incidence and dispersion of $B$. oleae in olive; therefore, we investigated these aspects on $B$. oleae. From this information, incidence-density relationships, the optimal sample sizes for estimating density, and a sequential sampling plan suitable for intensive population research and pest surveys were developed.

\section{Materials and methods}

\section{Experimental site}

Two 0.8 ha olive orchards in the Tarom Sofla $\left(36^{\circ} 23^{\prime} 0\right.$ " N, $49^{\circ} 14^{\prime}$ 0 " E) western part of Qazvin province, Iran with heavy infestation of $B$. oleae were selected. The trees was maintained under normal commercial practices for irrigation and fertilizer but not used any insecticides during the study period (from the early of March to the end of August 2012). The olive variety grown was Mari and the trees were 12-15 years old, 3-4 $\mathrm{m}$ tall and 6-7 $\mathrm{m}$ apart.

\section{Data collection}

\section{Adults}

For the purposes of studying the distribution of the adult olive fruit fly, six yellow sticky traps (about $5 " \times 10 "$ in size, covered with a nondrying sticky coating) plus both ammonium carbonate and pheromone (sex attractant) lures were randomly set up in each orchard. The traps separated from each other by $70 \mathrm{~m}$. To obtain a continuous release of the sex pheromone (1,7-dioxaspiro-[5,5]-undecane) into the environment, the traps were set under shade of plant canopy, placed at halfway the height of the olive trees canopy and oriented towards the upwind side. These traps were serviced weekly. The dispensers were replaced monthly, with a new one. The traps were in operation from March 2012 to August 2012 to monitor the fly population. On each sample date at each site, the number of adults caught was counted both on the internal and external sides of the traps and calculated the mean and variance as weekly. After each sampling, flies were trapped out of the trap to the next sample is not calculated. Each sticky trap was treated as a replicate. A total of 13 sets of data were obtained from each sampling location and was used to calculate dispersion indices. The analysis of spatial distribution was performed on the basis of the weekly captures.

\section{Immature (larvae)}

Sampling of larvae was carried out on sixteen trees. A total of 480 fruit from these trees were collected weekly from $11^{\text {th }}$ July to $3^{\text {rd }}$ October 2012. The samples were transferred to the laboratory and dissected and examined with a stereomicroscope to confirm for active and non-active infestation involving alive and dead larva. As adult, a total of 13 sets of data were obtained from each sampling location and the mean and variance were calculated.

\section{Spatial distribution}

To analyze the spatial dispersion, means $(\bar{X})$ and variances $\left(\mathrm{S}^{2}\right)$ for counts of adult (per pheromone trap) and larvae (per fruit), were calculated and used as basic data for models. We used and compared three common methods for describing the dispersion of $B$. oleae in the study site.

\section{Taylor's power law}

A power law function can be used to model the relationship between mean and variance as:

$\mathrm{S}^{2}=a \bar{X}^{b}$

where $S^{2}$ is the variance;

$\bar{X}$ the sample mean;

$a$ is a scaling factor related to sample size and $b$ measuring the species aggregation.

When $a=b=1, a>1, b<1$ and $a<1, b>1$, the distribution is random, regular and aggregated, respectively. Through use of a log transformation, one can estimate the coefficients with linear regression as:

$\log \left(\mathrm{S}^{2}\right)=\log (\mathrm{a})+\operatorname{blog}(\bar{X})$

where $a$ and $b$ are the parameters of the model, estimated by linearizing the equation after a log-log transformation (Taylor, 1961).

\section{Iwao's patchiness regression}

Iwao's regression method was used to quantify the relationship between mean crowding index $\left(\mathrm{X}^{*}\right)$ and mean density $(\bar{X})$ using the equation 3:

$\stackrel{*}{\mathrm{X}}=\alpha+\beta \bar{X}$

where $\alpha$ indicates the tendency to crowding (positive) or repulsion (negative) and $\beta$ reflects the distribution of population in space and is interpreted in the same manner as $b$ of Taylor's power law (Iwao, 1968). Student's $t$-test can be used to determine whether the adults are composed of single individuals and if adults are dispersed randomly.

Test $b=1: \mathrm{t}=(b-1) / \mathrm{SE}_{\mathrm{b}}$

and Test $\beta=1: \mathrm{t}=(\beta-1) / \mathrm{SE}_{\beta}$

where $\mathrm{SE}_{\mathrm{b}}$ and $\mathrm{SE}_{\beta}$ are the standard errors of the slope for the Taylor's power law and Iwao's patchiness regression, respectively. Calculated values are compared with tabulated t-values with $n-2$ degrees of freedom. If the calculated

$\mathrm{t}\left(\mathrm{t}_{\mathrm{c}}\right)<\mathrm{t}-$ table $\left(\mathrm{t}_{\mathrm{t}}\right)$

the null hypothesis $(b=1)$ would be accepted and spatial distribution would be random. If $t_{c}>t_{t}$, the null hypothesis would be rejected and if 
$b>1$ and $b<1$, the spatial distribution would be aggregated and uniform, respectively (Moradi-Vajargah et al., 2011).

\section{The $k$ exponent of the negative binomial distribution}

The parameter $k$ of the negative binomial distribution is one measure of aggregation that can be used for insect species having clumped or aggregated spatial pattern. When $k$ values are low and positive ( $k$ $<2)$ they indicate a highly aggregated population; $k$ values ranging from 2 to 8 indicate moderate aggregation; and values higher than $8(k$ $>8$ ) indicate a random population (Elliott, 1971; Southwood, 1995). The $k$ values were calculated by the moments method (Costa et al., 2010), and given by:

$k=\frac{\bar{X}^{2}}{S^{2}-\bar{X}}$

\section{Stability of the $k$ parameter}

In order to assure the stability of the $k$ parameter and increase our confidence in its suitability for adult counts we used Taylor procedure for testing this assumption. The parameter $k$ from the negative binomial distribution was regressed against the mean to determine whether estimates of $k$ and mean were related (Taylor et al., 1984).

\section{Common $k\left(k_{c}\right)$}

To test for the existence of a common $k\left(k_{c}\right)$ for both data sets, the estimate of the dispersion parameter $\mathrm{k}$ was linearly regressed on population mean $(\bar{X})$ as shown in Equation (8) (Tsai et al., 2000):

$k=c+d \bar{X}$

A $d$ value significantly $>0$ indicates the dependence of $k$ on mean density and justifies estimation of a common $k$. Estimates of $k_{c}$ were made using a regression method (Southwood, 1995; Afshari et al., 2009), which estimates $k_{c}$ by regressing

$y^{\prime}=S^{2}-\bar{X}$

on $x^{\prime}=\bar{X}^{2}-\left(S^{2} / N\right)$,

and $k_{c}$ was defined by $k_{c}=1 /$ slope (Southwood, 1995).

\section{Sampling plan development}

Determining the Taylor power law and Iwao's regression coefficients requires a large sample size (Ifoulis \& Savopoulou-Soultani, 2006). The coefficients from Iwao's regression were used to determine optimum sample size requirements necessary for estimating population means of $B$. oleae with fixed levels of precision (D). Precision was defined as:

$D=S_{\bar{X}} / \bar{X}$ where $S_{\bar{X}}$ is the standard error of the mean. D is a fixed proportion of the absolute mean of the population involved. It is also known as the allowable error, or fixed-precision level, with which the mean is measured (Krebs, 1999). A precision level of 0.10 is generally desired for research purposes while a precision level of 0.25 is generally accepted for pest sampling in pest management programs (Southwood, 1995); thus we tested these two precision levels in this study. The number of samples necessary to estimate the mean with two-fixed precision was determined by solving for Green's model (Green, 1970):

$$
n=\frac{a m^{b-2}}{D^{2}}
$$

where $a$ and $b$ are coefficients obtained from Taylor power law coefficients.

Because Iwao's regression coefficients provided the best explanation for the data, we developed sampling recommendations based on Kuno's formula (Kuno, 1991). The critical stop lines, the maximum number of samples required for fixed-precision sequential sampling plans were calculated using following equation:

$$
T_{n}=\left(1-\frac{n}{N}\right) \frac{(\alpha+1)}{D_{0}^{2}-\left(1-\frac{n}{N}\right)(\beta-1) / N}
$$

where $T_{n}$ is the critical cumulative number of individuals counted in $n$ samples, $\mathrm{N}=$ total of sample unit (12 and 16 for adult and larvae respectively) $\alpha$ and $\beta$ are coefficients obtained from the Iwao's regression coefficients and $\mathrm{D}$ is the required level of precision ( 0.10 and 0.25$)$.

\section{Results and discussion}

\section{Dispersion indices}

Iwao's patchiness regression revealed that the intercept value or the index of basic contagion $(\alpha)$ was negative for larvae $(\alpha=-1.04, P<0.001)$ (Table 1). The negative values indicated that for larvae $B$. oleae the basic component of the population tends to be a single individual. Further estimates for $\beta$, the density contagiousness coefficient, were significantly greater than unity $\left(\mathrm{t}_{\mathrm{c}}>\mathrm{t}_{\mathrm{t}}\right)$, in both stages $(\beta=1.06, \mathrm{P}<0.001$ for adult and $\beta=1.04, P<0.001$ for larvae) suggesting that the populations were over dispersed (Table 1).

Taylor's intercept was greater than zero (for adult, $a=1.22, \mathrm{P}<0.001$; for larvae, $a=0.01, \mathrm{P}<0.001$ ). In both stages, the slope or index of aggregation (b) was significantly $>1$ (for adult, $b=1.29, \mathrm{P}<0.001$; and $b=4.80, \mathrm{P}<0.001$ for larvae) $\left(\mathrm{t}_{\mathrm{c}}>\mathrm{t}_{\mathrm{t}}\right)$, thus confirming the aggregate nature of distribution (Table 1). In addition, the values of $1 / \mathrm{k}$ (reciprocal of $k$ derived from the negative binomial), was greater than zero, generally ranging between 0.33 and 2 for larvae and 0.17 and 1.24 for adult (Table 2). Overall, the results indicated aggregation of adult populations.

Table 1. Estimated values of parameters of Bactrocera oleae by regression analysis of Taylor's power law and Iwao's patchiness regression.

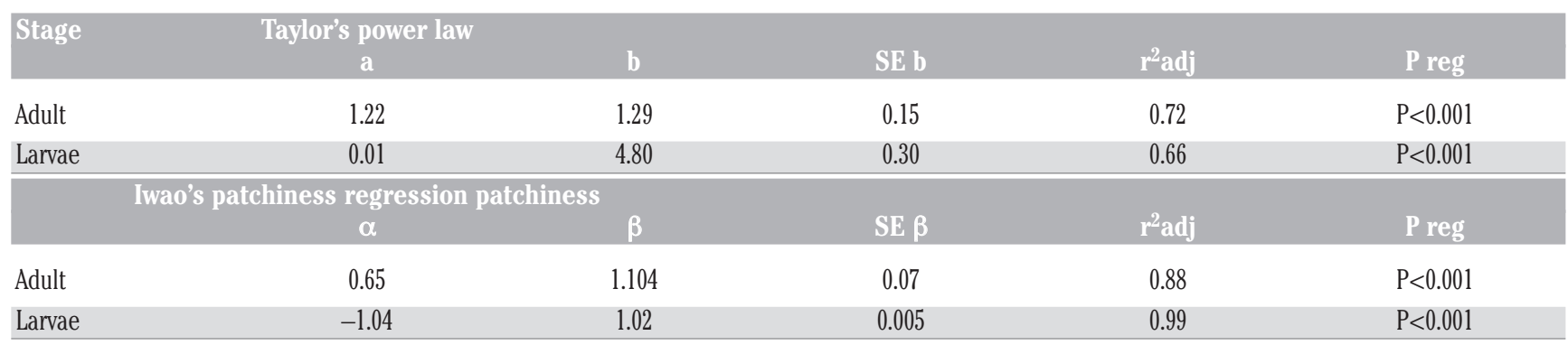


Aggregation was also reported for Bactrocera species affecting several crops (Dimou et al., 2003; Soemargono et al., 2011; Jahnke et al., 2014). Soemargono et al. (2011) that the distribution of Bactrocera dorsalis followed an aggregate pattern in mango. Jahnke et al. (2014) reported agrigation pattern for Anastrepha fraterculus (Dip.: Tephritidae) in common guava. Also similar observations were made by other researchers for other families of diptera. Such as: Namvar et al. (2011) for larvae Liriomyza sativae (Dip.: Agromyzidae) in cucumber, Lee et al. (2005) for larvae L. trifolli in cherry tomato, and Burgio et al. (2005) for larvae L. huidobrensis in lettuce.

The causes of aggregation as declared by Poole (1974), Southwood (1995), and Wratten and Fry (1980) were due to active aggregation of the fruit fly such as behavior whereby the presence of each individual male attracting to female, and reproductive biology were influenced by the heterogeneity of the environment such as microclimate especially relative humidity and preferred part of plant (Soemargono et al., 2011). Preferential oviposition of eggs on west-facing fruits resulting in significantly clustering larvae among fruits (Stonehouse et al., 2002) confirmed the presence of preferred part of plant. Pertaining to the behavior, it could be explained by the fact that the fruit flies caught in traps baited with methyl-eugenol, a highly potent attractant for the male fruit flies of several species, are mostly males (Stonehouse et al., 2002; Soemargono et al., 2011). The attraction of the traps may lead to overestimating the size of local populations due to migration of insects attracted from adjacent areas (Jenkins et al., 2011). Count data of larvae from infested fruit, as conducted in our study, may more realistically provide evidence of search and host selection behavior of the female fruit fly.

It is well known that the heterogeneity of the habitat is the most obvious cause of aggregation (Poole, 1974). Abiotic factors such as light,

Table 2. Estimated parameters dispersion indexes for Bactrocera oleae adult and larvae on different sampling dates in olive orchard.

\begin{tabular}{lcccc}
\hline Date & $k$ adult & Larvae & $1 / k$ adult & Larvae \\
21-Apr & 2.40 & 0.5 & 0.42 & 2 \\
28-Apr & 0.80 & 0.55 & 1.24 & 1.81 \\
\hline 04-May & 1.00 & 0.8 & 1.00 & 1.25 \\
11-May & 3.26 & 1.2 & 0.30 & 0.83 \\
\hline 18-May & 1.85 & 1.4 & 0.54 & 0.71 \\
25-May & 2.23 & 2.1 & 0.44 & 0.47 \\
\hline 01-Jun & 0.98 & 3 & 1.02 & 0.33 \\
08-Jun & 1.87 & 2.6 & 0.53 & 0.38 \\
\hline 15-Jun & 5.91 & 1.5 & 0.17 & 0.66 \\
22-Jun & 1.19 & 2.22 & 0.84 & 0.45 \\
\hline 29-Jun & 2.72 & 2.1 & 0.37 & 0.47 \\
05-Jul & 3.27 & 1.8 & 0.30 & 0.55 \\
\hline 12-Jul & 1.58 & 2 & 0.63 & 0.5 \\
\hline
\end{tabular}

The negative binomial distribution $(k)$ and the clumping index $(1 / k)$. Values for $1 / k$ can be random $(1 / k=0)$, aggregated $(1 / k>0)$ or uniform $(1 / k<0)$.

Table 3. $F$ and $P$ values of regression between aggregation index $k$ (dependent variable) and fly mean density (independent variable) and estimated common $\mathrm{k}, \boldsymbol{k}_{c}$.

\begin{tabular}{lcccc} 
Stage & $\begin{array}{c}\text { Regression } \\
\text { equation }\end{array}$ & $\mathrm{r}^{2}$ adj & P reg & $k_{c}$ \\
Adult & $k=15.19-4.36 \mathrm{~m}$ & 0.31 & $\mathrm{P}=54$ & 2.17 \\
Larvae & $k=5.88-0.21 \mathrm{~m}$ & 0.17 & $\mathrm{P}=0.14$ & 4.76 \\
\hline
\end{tabular}

temperature, wind, humidity and other ecological factors such as competition for food, predation and sexual stimuli, may influence the patterns of aggregation of individuals in a population (Jahnke et al., 2014).

\section{Estimation and stability of common $k\left(k_{c}\right)$}

The stability of $k$ is necessary to develop parametric sequential sampling methods (Nyrop et al., 1989), because $k$ is used to determine the minimum number of samples for which the mean density estimate has met a specific level of precision (Gonzalez-Andujar et al., 2006). There was no relationship between $k$ and $\bar{X}$ (for larva, $\mathrm{r}^{2}=0.17 ; \mathrm{P}=0.14$; for adult, $\mathrm{r}^{2}=0.31 ; \mathrm{P}=0.54$ ) and the slope of the regression of $k$ against the mean density per sample unit $(\bar{X})$, was not significantly greater than 0 , therefore, the calculation of a common $k\left(k_{c}\right)$ is acceptable (Table 3 ). The estimate of $k_{c}$ was 2.17 and 4.76 for adult and larvae, respectively (Table 3), so the hypothesis that there was a common $k_{c}$ was not rejected. The stability of $k$ implies that the degree of aggregation of the adult population was relatively constant, despite variation in sample means. According to Elliott (1971), the stability of $k$ implies that the degree of contagiousness in the population was relatively constant over several months despite the variation in sample means.

Therefore, in this current study, $k$ was an adequate model for the aggregation of the fruit fly. Similar test to confirm the stability of $k$ had been carried out by Soemargono et al. (2011) for the oriental fruit fly (B. dorsalis) distribution in mango plantation.

\section{Sequential sampling plans}

Optimum sample size (OSS) and critical stop lines: optimum ample size curves for fixed levels (10 and 25\%) of precision are shown in Figure 1. At a given level of precision, the optimum sample size decreased rapidly as fly density increased. For example, at a precision level of 0.25 that is suggested suitable for pest management purposes, for adult the OSS varied from the minimum of 2 samples in the late season when total population density was 20 flies/trap, to a maximum of 11 samples in early season when population density was 4 flies/trap. To achieve a desired precision level of 0.10 (recommended for research studies), the minimum and maximum of required sample increased to 7 and 15 flies/trap, respectively (Figure 1). For larvae, the OSS varied from the minimum of 47 samples (fruits) when total population density was 1.8 larvae/fruit, to a maximum of 63 samples when population density was 1.46 larvae/fruit. To achieve an upper precision level $(0.10)$, the minimum and maximum of required samples increased to 47 and 70, respectively (Figure 1).

The critical stop lines for the cumulative number of adults at precision level of 0.1 and 0.25 for both adult and larvae based on Iwao's patchiness regression are shown in Figure 2. The cumulative total number of fly $\left(\mathrm{T}_{\mathrm{n}}\right)$ collected in the trap/fruit is plotted on a graph as samples are collected. If the point $\left(n, T_{n}\right)$ is below the line for $D$, it is necessary to continue sampling until the fixed level of precision has been reached. By comparison, when it is above the line for $\mathrm{D}$, the mean can be estimated with Tn/n (Afshari et al., 2009).

\section{Conclusions}

Improved knowledge of the spatial distribution of $B$. oleae in olive fields coupled with the development of sequential sampling plans provides a foundation for more selective and efficient pest management options for growers. This study showed that $B$. oleae adults exhibit an aggregated behavior and follows a negative binomial distribution pattern. It could be inferred that this aggregated distribution is due to the behavior of fruit fly and some heterogeneity of the environment. The next steps are to develop an efficient scouting program and establish threshold densities for action that will inform growers on when the pest is active and when interventions (e.g., insecticides) can be applied. 

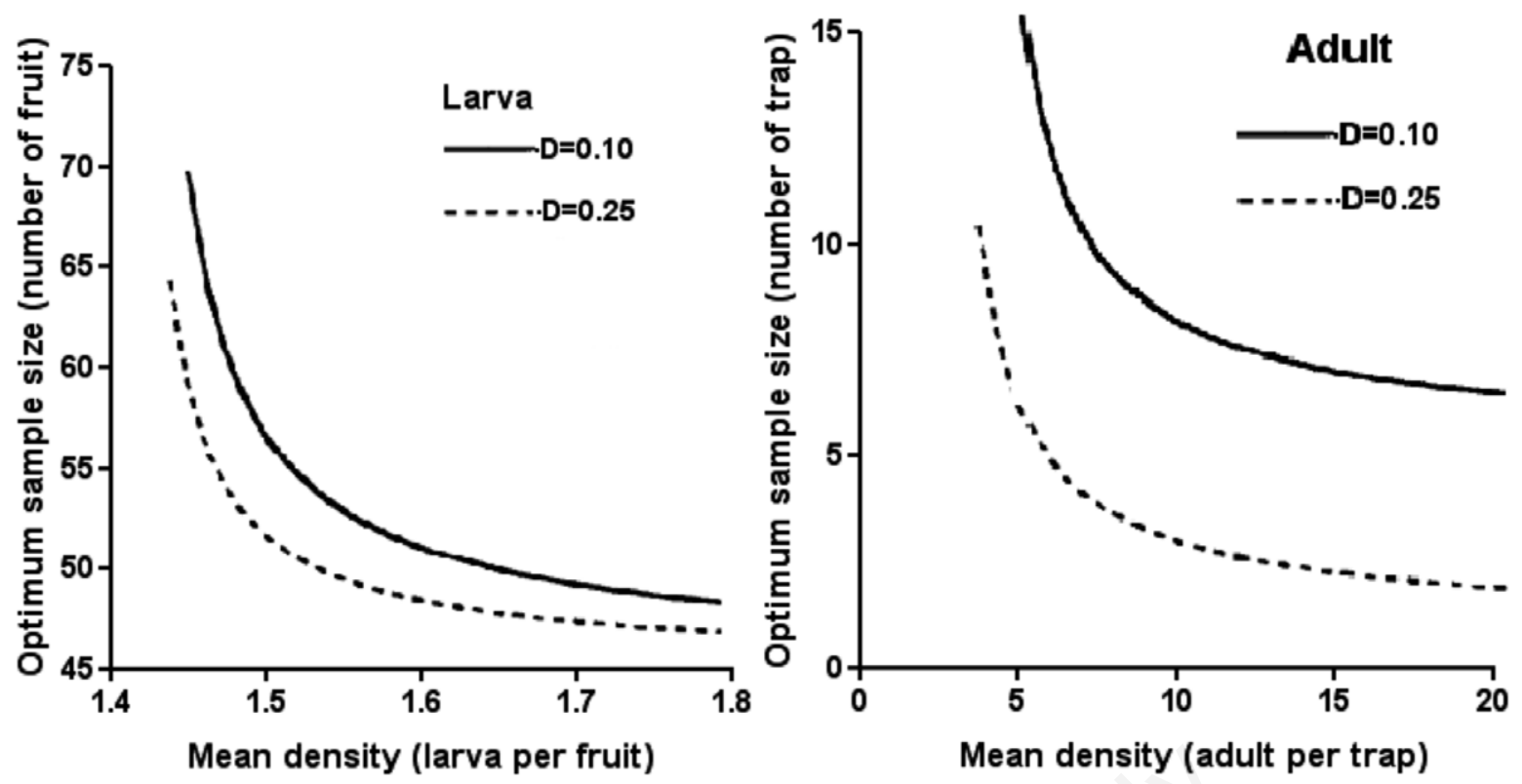

Figure 1. Relationship between Bactrocera oleae (larvae and adult) density and optimum sample size (n) for different levels of precision $(\mathrm{D}=0.10$ and 0.25$)$.
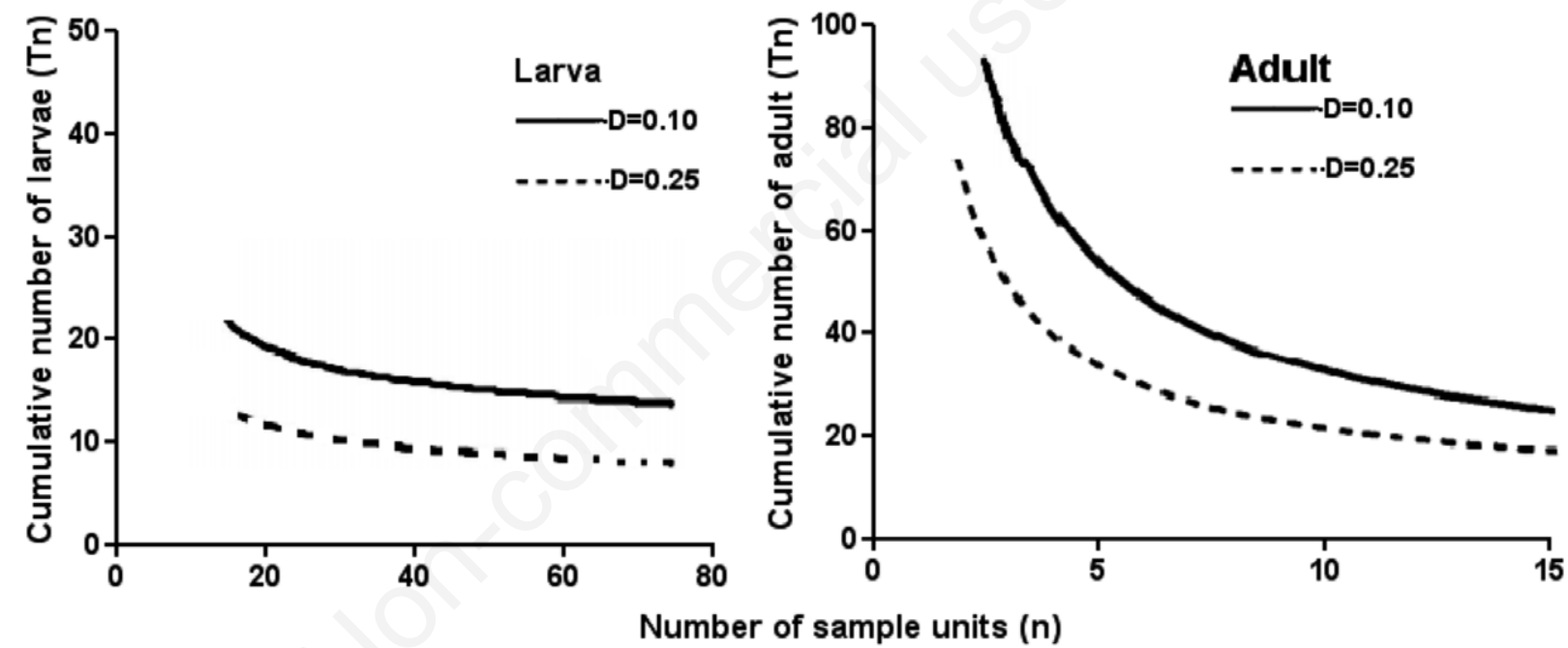

Figure 2. The stop lines for fixed-precision sequential sampling for larvae and adult population of Bactrocera oleae at two precision levels (0.10 and 0.25$)$ according to Kuno's model.

\section{References}

AFSHARI A., SOLEYMAN-NEJADIAN E, SHISHEBOR P., 2009 Population density and spatial distribution of Aphis gossypii Glover (Homoptera: Aphididae) on cotton in Gorgan, Iran. - J. Agric. Sci. Technol. 11: 27-38.

ARBAB A., 2014 - Spatial distribution and minimum sample size for overwintering larvae of the rice stem borer in paddy fields. Neotrop. Entomol. 43: 415-420.

ARBAB A., McNEILL M.R., 2014 - Spatial distribution and sequential sampling plans for adult Sitona humeralis Stephens (Coleoptera: Curculionidae) in alfalfa. - J. Asia Pacific Entomol. 17: 515-519.
BISSELEUA D.H.B., YEDE, VIDAL S., 2011 - Dispersion models and sampling of cacao mirid bug Sahlbergella singularis (Haglung) (Hemiptera: Miridae) on Theobroma cacao L. in southern Cameroon. - Environ. Entomol. 40: 111-119.

BURGIO G., LANZONI A., MASERTTI A., MANUCCI F., 2005 - Spatial patterns and sampling plan for Liriomyza huidobrensis (Diptera: Agromyzidae) and related parasitoids on lettuce. - Environ. Entomol. 34: 178-183.

BURRACK H.J., JOSEPH H., CONNELL F., ZALOM G., 2008 - Comparison of olive fruit fly (Bactrocera oleae (Gmelin)) (Diptera: Tephritidae) captures in several commercial traps in California. - Int. J. Pest Manage. 54: 227-234.

CALECA V., PICCIONELlO M.P., BATTAGLiA I., SIlVANA D., 2006 Survey on the control methods of Bactrocera oleae (Gmelin) in 
organic olive groves producing oil and table olives in Sicily. In: CARUSO T., AND MOTISI A. (Eds.), Proceedings of Olivebioteq 2006, Second International Seminar on Biotechnology and quality of olive tree products around the Mediterranean Basin, November $5^{\text {th }}-10^{\text {th }}$ Mazara del Vallo, Marsala: 2: 283-290.

CORRADO G., ALAGNA F., ROCCO M., RENZONE G., VARRICCHIO P., COPPOLA V., COPPOLA M., GARONNA A., BALDONI L., SCALONI A., RAO R., 2012 - Molecular interactions between the olive and the fruit fly Bactrocera oleae. - BMC Plant Biol. 12: 86.

COSTA M.G., BARBOSA J.C., YAMAMOTO P.T., LEAL R.M. 2010 - Spatial distribution of Diaphorina citri Kuwayama (Hemiptera: Psyllidae) in citrus orchards. - Sci. Agric. 67: 546-554.

DAANE K.M., J OHNSON M.W., 2010 - Olive fruit fly: managing an ancient pest in modern times. - Ann. Rev. Entomol. 55: 151-169.

DIMOU I.J., KOUTSIKOPOULOS C., ECONOMOPOULOS A., LYKAKIS J., 2003 - The distribution of olive fruit fly captures with MacPhail traps within an olive orchard. - Phytoparasitica. 31: 124-131.

ECONOMOPOULOS A.P., 2002 - The olive fruit fly, Bactrocera (Dacus) oleae (Gmelin) (Diptera: Tephritidae): its importance and control; previous SIT Research and Pilot Testing. - Report to International Atomic Energy Agency (IAEA), Vienna.

ELIOPOULOS P.A., 2007 - Evaluation of commercial traps of various designs for capturing the olive fruit fly Bactrocera oleae (Diptera: Tephritidae). - Int. J. Pest Manage. 53: 245-252.

ELLIOTT J.M., 1971 - Some methods for the statistical analysis of samples of the benthic invertebrates. - The Ferry House Ambleside, Westmorland: Freshwater Biological Association, Scientific Publication no. 25.

FERNANDES M.G., SPESSOTO R.R., DEGARANDE P.E., RODRIGUES T.R., 2011 - Sequential sampling of Aphis gossypii Glover (Hemiptera: Aphididae) and Frankliniella schultzei Trybom (Thysanoptera: Thripidae) on cotton crop. - Neotrop. Entomol. 40: 258-63.

GONZALEZ-ANDUJAR J.L., FERNANDEZ-QUINTANILLA C., NAVARRETE L., 2006 - Population cycles produced by delayed density dependence in an annual plant. - Am. Nat. 168: 318-322.

GREEN R.G., 1970 - On fixed precision level sequential sampling. - Res. Popul. Ecol. 12: 249-251.

IFOULIS A.A., SAVOPOULOU-SOULTANI M., 2006 - Developing optimum sample size and multistage sampling plans for Lobesia botrana (Lepidoptera: Tortricidae) larval infestation and injury in northern Greece. - J. Econ. Entomol. 99: 1890-1898.

ISRAELY N., ZIV Y., OMAN S.D., 2005 - Spatiotemporal distribution patterns of mediterranean fruit fly (Diptera: Tephritidae) in the central region of Israel. - Ann. Entomol. Soc. Am. 98: 77-84.

IWAO S., 1968 - A new regression method for analyzing the aggregation pattern of animal populations. - Res. Popul. Ecol. 10: 1-20.

JAFARI Y., REZAEE V., 2005 - First report of import olive flies to country. - Newslett. Entomol. Soc. Iran. 22: 1.

JAHNKE S., DEL PONTE M.E.M., REDAELLI L.R., REGO D.R.G.P., 2014 Spatial patterns and associations of Anastrepha fraterculus (Diptera: Tephritidae) and its parasitoid Doryctobracon areolatus (Hymenoptera: Braconidae) in organic orchards of Psidium guajava and Acca sellowiana. - Fla. Entomol. 97: 744-752.

JENKINS A.D., EPSKI N.D., KENDRA P.E., HEATH R.R., GOENAGA R., 2011 - Food-based lure performance in 3 locations in Puerto Rico: attractiveness to Anastrepha suspense and A. oblique (Diptera: Tephritidae). - Fla. Entomol. 94: 186-194.

KHAING 0., HORMCHAN P., JAMORNMARN S., WONGPIYASATID A., 2002 - Spatial dispersion and optimum sample size for cotton bollworm, Helicoverpa armigera (Hubner) (Lepidoptera: Noctuidae) larvae on cotton. - Kasetsart J. 36: 235-241.

KREBS C.J., 1999 - Ecological methodology, 2nd ed. - Addison-Wesley Educational.

KUNO E., 1991 - Sampling and analysis of insect populations. - Annu. Rev. Entomol. 36: 285-304.
LEE D.H., PARK J.J., PARK H., CHO K., 2005 - Estimation of leafmine density of Liriomyza trifolii in cherry tomato greenhouse using fixed precision sequential sampling plans. - J. Asia Pacific Entomol. 8: 81-86.

MONTIEL-BUENO A., 1986 - The use of sex pheromone for monitoring and control of olive fruit fly. In: Proc. Second Int. Symp. Fruit Flies, Crete, Greece. - Elsevier Science, Amsterdam: 483: 895.

MORADI-VAJARGAH M., GOLIZADEH A., RAFIEE-DASTJERDI H., ZALUCKI M.P., HASSANPOUR M., NASERI B., 2011 - Population density and spatial distribution pattern of Hypera postica (Coleoptera: Curculionidae) in Ardabil, Iran. - Not. Bot. Hort. Agrobot. Cluj. 39: 42-48.

NAMVAR P., SAFARALIZADEH M.H., BANIAMERI V., POURMIRZA A.A., KARIMZADEH ISFAHANI J., 2011 - Estimation of larval density of Liriomyza sativae Blanchard (Diptera: Agromyzidae) in cucumber greenhouses using fixed precision sequential sampling plans. Middle. East J. Sci. Res. 10: 157-163.

NO0RI H., 2011- Comparison between current insecticides for bait spray against olive fruit fly, Bactrocera oleae (Dip.: Tephritidae). Appl. Entomol. Phytopat. 79: 39-52.

NYROP J.P., AGNELLO A.M., KOVACH J., REISSIG W.H., 1989 - Binomial sequential classification sampling plans for European red mite (Acari: Tetranychidae) with special reference to performance criteria. - Econ. Entomol. 82: 482-490.

PAVLIDI N., DERMAUW W., ROMBAUTS S., CHRISARGIRIS A., Van LEEUWEN T., VONTAS J., 2013 - Analysis of the olive fruit fly Bactrocera oleae transcriptome and phylogenetic classification of the major detoxification gene families. - PLoS One 8: e66533.

PEDIGO, L.P., BUNTIN, G.D. (Eds.), 1994 - Handbook of sampling methods for arthropods in agriculture. - CRC Press, Boca Raton, FL: 616.

POOLE R.W., 1974 - Introduction to quantitative ecology. McGraw-Hill, New York, NY: 532.

SIRJANI F.O., LEWIS E.E., KAYA H.K., 2009 - Evaluation of entomopathogenic nematodes against the olive fruit fly, Bactrocera oleae (Diptera: Tephritidae). - Biol. Control 48: 274-280.

SOEMARGONO A., AHSOL HASYIM M., ISTIANTO M., 2011 - Spatial distribution pattern of the fruit fly, Bactrocera dorsalis complex (Diptera: Tephritidae) in mango orchard. - Agrivita 33: 207-213.

SOUTHWOOD T.R.E., 1995 - Ecological methods with particular reference to the study of insect populations. - ELBS and Chapman and Hall, London: 524.

STONEHOUSE J., MAHMOOD R., Poswal, A., MUMFORD, J.K.N., BALOCH, Z.M., MAKHDUM A.H., MUSTAFA G., HUGGETT D., 2002 - Farm field assessments of fruit flies (Diptera: Tephritidae) in Pakistan: distribution, damage and control. - Crop Protect. 21: 661-669.

TAYLOR L.R., 1961 - Aggregation, variance and the mean. - Nature 189: 732-735.

TAYLOR L.R., 1984 - Assessing and interpreting the spatial distribution of insect populations. - Annu. Rev. Entomol. 29: 321-357.

TSAI J.H., WANG J.J., IU Y.H.L., 2000 - Sampling of Diaphorina citri (Homoptera: Psyllidae) on orange jessamine in Southern Florida. Fla. Entomol. 83: 446-459.

VILLAMIL S.C, LEWIS E.E, ZALOM F.G., 2013 - Seasonal pheromone trap catches of male Bactrocera oleae (Diptera: Tephritidae) in northern California: asynchrony with host (olive tree) phenology? Environ. Entomol. 42: 1356-1362.

VINATIER F., TIXIER P., DUYCK P.F., LESCOURRET F., 2011 - Factors and mechanisms explaining spatial heterogeneity: a review of methods for insect populations. - Methods Ecol. Evol. 2: 11-22.

WRATTEN S.D., FRY G.L.A., 1980 - Field and laboratory exercises in ecology. - University Park Press, Baltimore, MD. 